\title{
XPS Characterization and Microhardness of Heat Treated Co-W Coatings Electrodeposited with Gluconate Bath
}

\author{
H. Seenivasan ${ }^{\text {a }}$ Parthasarathi Bera*, J. N. Balaraju, and K. S. Rajam \\ Surface Engineering Division, CSIR-National Aerospace Laboratories, Bangalore 560017, \\ India
}

\begin{abstract}
Thermal stability and effect of heat treatment on electronic structure and microhardness of electrodeposited $\mathrm{Co}-\mathrm{W}$ alloy coatings using gluconate bath was characterized by DSC and XPS. XPS studies demonstrate that as-deposited alloy coating has significant amount of Co and $\mathrm{W}$ metals as well as $\mathrm{Co}^{2+}$ and $\mathrm{W}^{6+}$ species. There is a decrease in Co metal concentration in the alloy heated at $600{ }^{\circ} \mathrm{C}$ and $\mathrm{Co}$ is in fully oxidized form when it is heat treated at 800 ${ }^{\circ} \mathrm{C}$. Marginal decrease in $\mathrm{W}$ metal concentration and presence of both $\mathrm{W}^{6+}$ and $\mathrm{W}^{5+}$ species are observed when the coating is heated at $600{ }^{\circ} \mathrm{C}$, whereas mostly $\mathrm{W}^{6+}$ species along with a little amount of $\mathrm{W}^{5+}$ could be seen in the coating heated at $800{ }^{\circ} \mathrm{C}$. Microhardness values of 1017 and $1336 \mathrm{HK}$ are observed when $\mathrm{Co}-\mathrm{W}$ coatings are heated at 500 and $600{ }^{\circ} \mathrm{C}$, respectively and they are comparable with as-deposited hard chromium coatings.
\end{abstract}

KEYWORDS: Co-W coating; Heat treatment; DSC; XPS; Microhardness

*Corresponding author

Tel: +91-80-25086359, Fax: +91-80-25210113, E mail: partho@nal.res.in (P. Bera)

${ }^{a}$ Present address: Department of Chemical Sciences, Indian Institute of Science Education and Research Kolkata, Mohanpur 741252, West Bengal, India 


\section{INTRODUCTION}

In recent years, nanocrystalline Co alloys have attracted much attention due to their magnetic, mechanical, corrosion and wear resistant properties and thermal stability. ${ }^{1-9}$ They have also been used in aerospace and autobody components production as anticorrosive protectors. Among Co alloy materials, Co-W alloys have attracted much attention due to their exceptional hardness, wear resistant and corrosion resistant behaviour. ${ }^{5-8}$ Moreover, Co-W alloy deposits have been identified as one of the promising replacements for the conventional hard chromium deposits which are formed in an environmentally hazardous process based on hexavalent chromium. ${ }^{5-7}$ It has been observed that codeposition of hard material such as W with Co could enhance the thermal stability, electrochemical and mechanical properties of Co-W alloy coatings.

It is very well documented in the literature that heat treatment influences the structure, composition and the properties of alloys. Heat treatment in the electrodeposited Co-W and Co-W-P alloys enhances the corrosion resistance and this enhancement is attributed to the formation of stoichiometric compounds, surface oxides and the precipitation of stable phases in the microcracks. ${ }^{10-12}$ Recently, we have studied the structure and morphology of heat treated $\mathrm{Co}-\mathrm{W}$ coatings prepared by gluconate bath and found that there is no change in the structure till $500{ }^{\circ} \mathrm{C}$ and a remarkable change for the coating heat treated at $800{ }^{\circ} \mathrm{C} .{ }^{13}$ This has led us to study systematically for the understanding of such behaviour of this system. In the present work, we report details of thermal stability, systematic research on electronic structure, elemental oxidation states, their relative concentrations and microhardness of Co-W alloy coatings after heat treatment at different temperatures using DSC and XPS techniques. Increase in microhardness in heat treated coatings is substantiated by XPS results. 
It has also been found that heat treated Co-W alloy coatings show comparable microhardness of hard chromium coatings.

\section{EXPERIMENTAL METHODS}

Co-W alloy coatings were electrodeposited from baths containing cobalt sulfate heptahydrate $\left(15 \mathrm{~g} \mathrm{~L}^{-1}\right)$, sodium tungstate dihydrate $\left(16.5 \mathrm{~g} \mathrm{~L}^{-1}\right)$, boric acid $\left(40 \mathrm{~g} \mathrm{~L}^{-1}\right)$, sodium gluconate $\left(110 \mathrm{~g} \mathrm{~L}^{-1}\right)$ and sodium chloride $\left(30 \mathrm{~g} \mathrm{~L}^{-1}\right)$. The $\mathrm{pH}$ of prepared bath was around 5.2 and the $\mathrm{pH}$ was adjusted to $5.0 \pm 0.05$ by the addition of $\mathrm{H}_{2} \mathrm{SO}_{4}$. Analytical grade chemicals and deionized water were used to prepare the baths. For electrodeposition, approximately $200 \mathrm{~mL}$ solution was taken in a $250 \mathrm{~mL}$ glass beaker. Temperature of the bath was maintained at 80 ${ }^{\circ} \mathrm{C}$ using a constant temperature water bath. A graphite bar was used as the anode and a mechanically buffed brass sheet with $10 \mathrm{~cm} \times 2.5 \mathrm{~cm} \times 0.1 \mathrm{~cm}$ dimension was used as the substrate. For XPS and DSC studies plating was done on stainless steel substrates. The coating was peeled off from the substrate for analysis. Heat treatment studies were carried out on the coatings deposited on mild steel substrates. In all cases, substrate was degreased with acetone, rinsed with tap and deionized water, cathodically cleaned with $10 \% \mathrm{NaOH}$ solution for $1 \mathrm{~min}$ at $15 \mathrm{~A} \mathrm{dm}^{-2}$, rinsed with tap and deionized water. Then the substrate was deoxidized with 10 vol. $\% \mathrm{H}_{2} \mathrm{SO}_{4}$ for $30 \mathrm{~s}\left(50\right.$ vol. $\% \mathrm{H}_{2} \mathrm{SO}_{4}$ for $5 \mathrm{~s}$ for stainless steel and mild steel substrates), rinsed with tap water and deionized water and loaded in the bath for electroplating. Electrodeposition was carried out by direct current (DC) electrodeposition method. DC electrodeposition was carried out galvanostatically by using an Aplab 7253 regulated DC power supply at an average applied current density of $4.7 \mathrm{~A} \mathrm{dm}^{-2}$. The plating was carried out for $1 \mathrm{~h}$ and the deposited coating was rinsed with deionized water and dried at room temperature. 
The heat treatment temperatures were identified and chosen from DSC curves. The thermal stabilities of $\mathrm{Co}-\mathrm{W}$ coatings were studied at $160,350,500,600$ and $800{ }^{\circ} \mathrm{C}$ with vacuum of $5 \times 10^{-4} \mathrm{~Pa}$. Molybdenum strips were used as heating elements to heat a stainless steel 316 thick plate, on which the test samples were placed. The accuracy of the set temperature was $\pm 10^{\circ} \mathrm{C}$. Heat treatment was done for $1 \mathrm{~h}$ with heating and cooling rates of 5 ${ }^{\circ} \mathrm{C} \min ^{-1}$.

Differential scanning calorimetry (DSC) studies for the phase transformation of these Co-W alloy coatings were performed with a Diamond DSC (Perkin Elmer). The sample was taken in the form of a foil and cut into smaller pieces. About $0.5 \mathrm{~g}$ sample was put in an aluminium pan and crimped using a cover. Empty aluminium pan with cover crimped was used as a reference. The crimped specimen and reference samples were placed in a Pt furnace and heated with different scanning rates of $10,20,30$ and $40{ }^{\circ} \mathrm{C} \mathrm{min}-1$ under continuous purging of the heating chamber with nitrogen flow of $30 \mathrm{~mL} \mathrm{~min}^{-1}$ to avoid sample oxidation. The plot of temperature against heat flow was obtained.

X-ray photoelectron spectroscopy (XPS) of as-deposited and heat-treated Co-W alloy coatings were recorded with a Thermo Fisher Scientific Multilab 2000 spectrometer using non-monochromatic $\mathrm{AlK} \alpha$ radiation $(1486.6 \mathrm{eV})$ as an X-ray source operated at $150 \mathrm{~W}$ (15 $\mathrm{kV}$ and $10 \mathrm{~mA})$. The binding energies $\left(\mathrm{E}_{\mathrm{B}}\right)$ reported here were calculated with reference to $\mathrm{C} 1 \mathrm{~s}$ peak at $284.5 \mathrm{eV}$ with a precision of $\pm 0.1 \mathrm{eV}$. For XPS analysis, coatings were mounted on the sample holder after cutting into small pieces and they were kept in the preparation chamber with ultrahigh vacuum (UHV) at $10^{-9}$ Torr for $5 \mathrm{~h}$ in order to desorb any volatile species present on the surface. After $5 \mathrm{~h}$, samples were transferred into the analyzer chamber with UHV at $10^{-9}$ Torr. All the spectra were obtained with pass energy of $30 \mathrm{eV}$ and step increment of $0.05 \mathrm{eV}$. The experimental data were curve fitted with Gaussian peaks after 
subtracting a linear background employing PeakFit v4.11 program. For Gaussian peaks, slightly different full width at half maximum (FWHM) was used for different chemical states. The spin-orbit splitting and doublet intensities were fixed as given in the literature. ${ }^{14}$

Microhardness measurements of these alloy coatings heated with different temperatures were carried out on the surface of the deposits using Buehler microhardness tester with a Knoop indenter under a test load of $50 \mathrm{~g}$ for $15 \mathrm{~s}$. For microhardness measurements, samples were polished with $0.3 \mu \mathrm{m} \mathrm{Al}_{2} \mathrm{O}_{3}$ until mirror finishing was obtained. Average hardness (HK) value was estimated by making 5 indents on each sample.

\section{RESULTS AND DISCUSSION}

\subsection{Chemical composition, structural and morphological studies}

Effects of heat treatment on chemical composition, structure and morphology of $\mathrm{Co}-\mathrm{W}$ coatings are discussed in details in our previous paper. ${ }^{13}$ In brief, EDXS analysis demonstrates an increase in tungsten content in alloy coatings after heating at 600 and $800{ }^{\circ} \mathrm{C}$ and $\mathrm{W}$ concentration is in the range of $46-59 \mathrm{wt} . \%$ in as-deposited and heat treated coatings. XRD patterns indicate the presence of amorphous structure in as-deposited coating and the coatings heated up to $500{ }^{\circ} \mathrm{C}$, whereas $\mathrm{Co}_{3} \mathrm{~W}$ phase could be observed in the coatings heat treated at 600 and $800{ }^{\circ} \mathrm{C}$. Electrodeposited $\mathrm{Co}-\mathrm{W}$ coating consists of spherical and smooth bright nodules on its surface and is crack-free as seen from FESEM image, but cracks could be observed in the coatings heat treated at higher temperatures.

\subsection{Thermal stability studies}

It is well known that the metastable alloys, which are thermodynamically unstable, undergo phase transformation to become completely stable crystalline phase. DSC is a very useful tool to study the phase transformation behaviour of such metastable alloys. The DSC thermogram 
of Co-W deposits, recorded over a temperature range of 100 to $575^{\circ} \mathrm{C}$ at a scan rate of $20{ }^{\circ} \mathrm{C}$ $\min ^{-1}$ is shown in Figure 1. The presence of exothermic peaks suggests the occurrence of phase transformation. The peak temperatures and the corresponding enthalpy $(\Delta \mathrm{H})$ values are compiled in Table I. From the figure it is evident that the deposit displays two exothermic peaks at 159 and $335{ }^{\circ} \mathrm{C}$ and the corresponding enthalpy values are -11.5 and $-5.4 \mathrm{~J} \mathrm{~g}^{-1}$, respectively. Deposit has also exhibited the presence of one endothermic peak at $493{ }^{\circ} \mathrm{C}$ with an enthalpy value of $49.8 \mathrm{~J} \mathrm{~g}^{-1}$. From the figure it is evident that the two exothermic peaks present are very shallow and are not very prominent. The presence of these exothermic peaks could be attributed to the structural relaxation such as annihilation of point defects and dislocations within the grains and grain boundary zones. In this sense, the increase in the crack density at higher heat treatment temperatures observed from our FESEM studies ${ }^{13}$ is well augmented by the shallow exothermic peaks obtained in the DSC curve and this increased crack density is due to the internal movements in the Co-W deposits upon heat treatment. It has also been observed that by varying the scan rate there is no significant change in the intensity of exothermic peaks. On the other hand, there is an appreciable change in the endothermic peak intensity at higher scan rates. From this it is evident that the crystalline transformation is not significant in the electrodeposited $\mathrm{Co}-\mathrm{W}$ alloy in the temperature range up to $500{ }^{\circ} \mathrm{C}$. Similar observation has been noticed in the XRD patterns obtained for these deposits annealed until $500{ }^{\circ} \mathrm{C} .{ }^{13}$ The endothermic peak observed in all the four coatings might have formed due to increased disorderliness in the coating at this temperature. Increase in disorderliness actually means the increase in entropy of a system. Thermodynamics proves that the increase in disorderliness (entropy) of a system is accompanied by heat intake by the system which conforms to the appearance of the endothermic peak. 
Chen et al. ${ }^{15}$ and Singh et al. ${ }^{16}$ have reported that there is a possibility of glass formation and melting point depression of electrodeposited $\mathrm{Co}-\mathrm{W}$ alloy coatings. Chen et al. ${ }^{15}$ have noticed that the strong interaction with atoms of different atomic sizes which constitutes the eutectic composition produces a large melting point depression. Singh et. al. ${ }^{16}$ have calculated the glass forming range to be $40-70$ at. $\% \mathrm{~W}$ from the size difference rule, whereas the experimental results indicate the glass forming ability (GFA) of Co-W alloys at 20 at. $\% \mathrm{~W}$. Therefore, it could be suggested that the electrodeposited $\mathrm{Co}-\mathrm{W}$ coatings might have a very low melting point like $500{ }^{\circ} \mathrm{C}$ as seen from the DSC curves. Fedosyuk et al. observed low crystallization temperature of around $400{ }^{\circ} \mathrm{C}$ for $\mathrm{Co}-\mathrm{W}$ coatings with low tungsten content obtained from citrate baths. ${ }^{17}$ The authors in their study also found that this crystallization temperature increased with increasing $\mathrm{W}$ concentration (for 28 at.\% W), crystallization started at approximately $450{ }^{\circ} \mathrm{C}$ ). Thus, coatings obtained from gluconate bath in this study are stable up to $500^{\circ} \mathrm{C}$.

\subsection{XPS studies}

To get the clear idea about effect of heat treatment on the electronic structure of $\mathrm{Co}-\mathrm{W}$ alloys, XPS studies of as-deposited and heat-treated coatings have been carried out. We have done XPS of samples heated at 600 and $800{ }^{\circ} \mathrm{C}$ as there is no significant change in the XRD patterns of coatings heated up to $500{ }^{\circ} \mathrm{C} .{ }^{13} \mathrm{XPS}$ of $\mathrm{Co} 2 \mathrm{p}$ core level region in as-deposited Co-W alloy coating and the same after heat treatment at 600 and $800{ }^{\circ} \mathrm{C}$ could be deconvoluted into sets of spin-orbit doublets along with associated satellite (S) peaks. Deconvoluted core level spectrum of Co2p in as-deposited Co-W coating and the same coating after heat treatment at $800{ }^{\circ} \mathrm{C}$ is shown in Figure 2. Accordingly, in the as-deposited coating, Co2 $\mathrm{p}_{3 / 2,1 / 2}$ peaks at 778.3 and $793.1 \mathrm{eV}$ with spin-orbit separation $\left[\Delta \mathrm{E}_{\mathrm{B}}\left(2 \mathrm{p}_{3 / 2}-2 \mathrm{p}_{1 / 2}\right)\right]$ of $14.8 \mathrm{eV}$ correspond to Co metal, whereas peaks at 781.7 and $797.6 \mathrm{eV}$ with $15.9 \mathrm{eV}$ spin- 
orbit separation could be assigned for $\mathrm{Co}^{2+}$ from highly ionic $\mathrm{Co}^{2+}$ type of species present in this kind of coatings. ${ }^{18-20}$ On the basis of $2 \mathrm{p}_{3 / 2,1 / 2}$ peak positions at $780.5 \pm 1.5$ and $796.0 \pm$ $1.5 \mathrm{eV}$, respectively, oxidized Co species could be distinguished from metallic Co. Previous studies have reported that differences in the $2 \mathrm{p}$ peak positions between $\mathrm{Co}^{2+}$ and $\mathrm{Co}^{3+}$ vary from 0.1 to $1.5 \mathrm{eV}$ making it difficult to use the primary $2 \mathrm{p}$ peaks to distinguish between $\mathrm{CoO}$ and $\mathrm{Co}_{3} \mathrm{O}_{4}$. These two oxides can be distinguished, however, by differences in satellite features. The $\mathrm{Co} 2 \mathrm{p}$ spectrum of $\mathrm{CoO}$ contains prominent satellite peaks which are separated approximately by $4-6 \mathrm{eV}$ higher in energy than the primary peaks. In the present asdeposited coating, the binding energy separation between $\operatorname{Co} 2 \mathrm{p}_{3 / 2}$ and its corresponding satellite $\left[\Delta \mathrm{E}_{\mathrm{B}}\left(2 \mathrm{p}_{3 / 2}-\mathrm{S}\right)\right]$ is $4.3 \mathrm{eV}$. These satellite features arise from shake-up phenomenon in which the excitation of unpaired valence electrons increases the number of relaxed final states. While $\mathrm{Co}_{3} \mathrm{O}_{4}$ also exhibits satellite peaks due to the $\mathrm{Co}^{2+}$ contribution, they are considerably less intense and situated $9-10 \mathrm{eV}$ higher than the primary peaks. Therefore, oxidized $\mathrm{Co}$ is in +2 oxidation state in the as-deposited coating. Binding energies, relative intensities and FWHMs of different Co species as observed from Co2p spectra of Co-W coating subjected to heat treatment at different temperatures are summarized in Table II. Relative intensities in the table indicate the decrease in Co metal concentration along with simultaneous increase in Co oxide species when the coating is heat treated at $600{ }^{\circ} \mathrm{C}$, whereas only oxidized Co species is present in the core level spectrum of the coating heated at $800{ }^{\circ} \mathrm{C}$. Presence of oxidized Co species in the sample heated at $800{ }^{\circ} \mathrm{C}$ could be confirmed from the deconvoluted Co2p spectrum shown in Figure 2 (b).

$\mathrm{W}_{4 \mathrm{f}_{7 / 2,5 / 2}}$ core level peaks at $31.4,33.6$ and $36.1,38.3 \mathrm{eV}$ in as-deposited spectrum could be assigned for elemental $\mathrm{W}$ and $\mathrm{W}^{6+}$ species, respectively. ${ }^{19,21}$ Change in $\mathrm{W} 4 \mathrm{f}$ peak characteristics could be observed in the coatings heated at 600 and $800{ }^{\circ} \mathrm{C}$. A broad spectral 
envelop in the higher binding energy region of W4f along with lower binding energy peaks in the coating heated at $600{ }^{\circ} \mathrm{C}$ indicates the presence of multiple oxidation states of $\mathrm{W}$ in this coating. The entire spectrum could be deconvoluted into three sets of spin-orbit doublets of several W components. Deconvoluted core level spectra of W4f in as-deposited Co-W coating and the same coating after heat treatment at $600{ }^{\circ} \mathrm{C}$ are displayed Figure 3 . Accordingly, $\mathrm{W}_{4} \mathrm{f}_{7 / 2,5 / 2}$ peaks at $31.0,33.0 ; 35.5,37.7$ and $36.8,38.9 \mathrm{eV}$ could be ascribed to $\mathrm{W}^{0}, \mathrm{~W}^{5+}$ and $\mathrm{W}^{6+}$ oxidation states, respectively. ${ }^{22}$ Similarly, $\mathrm{W}_{4} \mathrm{f}_{7 / 2,5 / 2}$ peaks at $35.8,38$ and $36.4,38.5 \mathrm{eV}$ observed in the coating heated at $800{ }^{\circ} \mathrm{C}$ indicate the presence of $\mathrm{W}^{5+}$ and $\mathrm{W}^{6+}$ only. It is important to note that metallic $\mathrm{W}$ species is absent in the coating after heattreatment at $800{ }^{\circ} \mathrm{C}$ indicating that $\mathrm{W}$ is fully oxidized at this temperature. Binding energies, relative intensities and FWHMs of different W species as observed from W4f spectra of Co-W alloy coating subjected to heat treatment at different temperatures are summarized in Table III.

XPS of O1s core level spectra of as-deposited as well as heat treated coatings could be deconvoluted into several components and are shown in Figure 4. The as-deposited coating shows main peak at $532.1 \mathrm{eV}$ that corresponds to oxygen associated with hydroxyl $\left(\mathrm{OH}^{-}\right)$group, whereas small peaks at 530.7 and $533.4 \mathrm{eV}$ could represent oxygen corresponding to $\mathrm{CoO}$ and $\mathrm{H}_{2} \mathrm{O}$ species associated with the sample, respectively. ${ }^{23}$ A small peak above $535 \mathrm{eV}$ corresponds to NaKLL peak coming from $\mathrm{Na}$ salt in bath solution taken during electrodeposition. ${ }^{24}$ There is a marginal change in relative intensities of several oxygen components after heat treatment.

Relative surface concentrations of Co and $\mathrm{W}$ in as-deposited and heat treated $\mathrm{Co}-\mathrm{W}$ alloy coatings have been estimated by the relation: ${ }^{25}$ 


$$
\frac{C_{C o}}{C_{W}}=\frac{I_{C o} \sigma_{W} \lambda_{W} D_{W}}{I_{W} \sigma_{C o} \lambda_{C o} D_{C o}}
$$

where $\mathrm{C}, \mathrm{I}, \sigma, \lambda$ and $\mathrm{D}$ are the surface concentration, intensity, photoionization cross-section, mean escape depth and analyser detection efficiency, respectively. Integrated intensities of Co2p and W4f peaks have been taken into account to estimate the concentration, whereas photoionization cross-sections and mean escape depths have been obtained from the literature. ${ }^{26,27}$ The geometric factor was taken as 1 , because the maximum intensity in this spectrometer is obtained at $90^{\circ}$. Relative surface concentrations (at.\%) of $\mathrm{Co}$ and $\mathrm{W}$ in $\mathrm{Co}-\mathrm{W}$ alloy coatings with different heat treatment temperatures are shown in Table IV.

\subsection{Microhardness studies}

Microhardness measurements were carried out with the surface of the as-deposited and heat treated $\mathrm{Co}-\mathrm{W}$ deposits and the values are given in Table V. Co-W alloy exhibits a hardness value of $486 \pm 20 \mathrm{HK}$ in as-deposited condition. The hardness obtained is higher than electrodeposited Co $(\sim 300 \mathrm{HK})$ and the value agrees well with the values in literature. ${ }^{5} \mathrm{~A}$ marginal increase in hardness could be seen for the deposit annealed at $160{ }^{\circ} \mathrm{C}$ and approximately $45 \%$ increase in the hardness value could be noticed for the deposit annealed at $350{ }^{\circ} \mathrm{C}$. Deposit annealed at $500{ }^{\circ} \mathrm{C}$ exhibits more than $100 \%$ increase in hardness value. Very high hardness value in comparison with as-deposited sample is obtained when deposit is heated at $600{ }^{\circ} \mathrm{C}$. Variation of microhardness of $\mathrm{Co}-\mathrm{W}$ alloy coatings with heat treatment temperatures is shown in Figure 5. Within this context, increasing trend in hardness in heat treated $\mathrm{Co}-\mathrm{W}$ coatings is contrary to the behaviour of heat treated hard chromium coatings. It was well documented that hard chromium coatings exhibited very high hardness values of $\sim 1000 \mathrm{HV},{ }^{28,29}$ but hardness values decreased drastically upon heat treatment. ${ }^{29}$ Hardness of conventional chromium coating decreased to $810,585,270,100 \mathrm{HV}$ when it was heated at 
200, 400, 600 and $800{ }^{\circ} \mathrm{C}$, respectively. ${ }^{29}$ Chromium coatings showed a structure dependency of hardness, ${ }^{30}$ while high dislocation densities were reported to be the reasons for high hardness. ${ }^{31,32}$ But heat treatment caused the formation of fine equiaxed grain structure, resulting in softening (decrease in hardness) due to recrystallization which was considered to be the main cause for the decrease in hardness of annealed chromium coatings. ${ }^{32}$

In present study, amount of $\mathrm{W}$ ranges in 46-59 wt.\% which indicates that Co and $\mathrm{W}$ are either in solid solution form or $\mathrm{Co}_{3} \mathrm{~W}$ phase. From the $\mathrm{Co}-\mathrm{W}$ phase diagram, ${ }^{33}$ it is clear that cobalt and tungsten (W content: $48-51$ wt.\%) remain in $\mathrm{Co}_{3} \mathrm{~W}$ phase. Therefore, the higher microhardness values shown by annealed Co-W deposits until $500{ }^{\circ} \mathrm{C}$ could be due to the solid solution form of $\mathrm{W}$ in Co which can be further confirmed with XRD patterns. ${ }^{13}$ Again, significant increase in microhardness has been observed when as-deposited coating is heat treated at 160,350 and $500{ }^{\circ} \mathrm{C}$ though there is no structural change up to $500{ }^{\circ} \mathrm{C}$. It could be attributed to changes in structural relaxation such as annihilation of point defects and dislocations within the grains and grain boundary zones as revealed by DSC studies. On the other hand, very high hardness observed in deposits annealed at higher heat treatment temperatures could be reasoned with the formation of $\mathrm{Co}_{3} \mathrm{~W}$ phase. Relative surface concentrations evaluated from the XPS studies demonstrate that Co is segregated over the alloy surface in the as-deposited coating and its concentration decreases upon heat treatment at $600{ }^{\circ} \mathrm{C}$ (Table IV). Concentrations of Co and W calculated from XPS of the coating heated at $600{ }^{\circ} \mathrm{C}$ could hint the formation of $\mathrm{Co}_{3} \mathrm{~W}$ phase over the surface at this temperature. Further heat treatment at $800{ }^{\circ} \mathrm{C}$ slightly increases the surface Co concentration. Again, $67 \%$ of hard material $\mathrm{W}$ species is in alloyed form in the coating heat treated at $600{ }^{\circ} \mathrm{C}$ (Table III) that could be the one of the reasons for high hardness at this temperature. However, hardness 
values measured in Co-W coatings heat treated at 500 and $600{ }^{\circ} \mathrm{C}$ could be comparable with as-deposited conventional hard chromium coatings.

\section{CONCLUSIONS}

Low temperature region exothermic peaks in DSC curve of $\mathrm{Co}-\mathrm{W}$ alloy coating are related to internal movement in the coating, whereas increased disorderliness and possible melting lead to endothermic peak observed at higher temperature. XPS studies demonstrate the presence of mainly oxidized species of $\mathrm{Co}$ and $\mathrm{W}$ in the heat treated coatings, whereas as-deposited coating contains both metallic and oxidized species. Nature of surface species and their compositions in $\mathrm{Co}-\mathrm{W}$ deposits vary with heat treatment temperatures. Heat treatment influences the oxidation states and their relative concentrations. Relative surface concentrations of Co and W evaluated from XPS demonstrates that Co is segregated on the surface of the coatings and it varies with different heat treatment temperatures. Presence of alloyed species in terms of solid solution and $\mathrm{Co}_{3} \mathrm{~W}$ phase enhances microhardness of heat treated coatings very significantly. High hardness in the coating heat treated at $600{ }^{\circ} \mathrm{C}$ is due to greater amount of alloyed $\mathrm{W}$ species present in the coating. Increase in microhardness of the coatings heated up to $500{ }^{\circ} \mathrm{C}$ is due to change in structural relaxation. Hardness of heat treated $\mathrm{Co}-\mathrm{W}$ coatings could be comparable with hazardous hard chromium coatings as they have higher hardness values.

\section{ACKNOWLEDGMENTS}

Authors wish to thank the Director, CSIR-National Aerospace Laboratories for giving permission to publish this work. The authors acknowledge Dr. Harish C. Barshilia and Mr. N. Selvakumar of CVD-PVD laboratory for providing vacuum furnace and also thank Mr. 
Manikandanath for recording DSC profiles. Authors are thankful to Prof. M. S. Hegde, Indian Institute of Science, Bangalore for providing XPS facility.

\section{References}

1. X. Xu and C. Zangari, J. Appl. Phys. 99, 08M304 (2006).

2. V. G. Shadrov, A. V. Boltushkin and L. V. Nemtsevich, Russian Metall. 2006, 271 (2006).

3. I. Kosta, E. Vallés, E. Gómez, M. Sarret and C. Müller, Mater. Lett. 65, 2849 (2011).

4. M. da Silva, C. Wille, U. Klememt, P. Choi and T. Al-Kassab, Mater. Sci. Eng. A 445-446, 31 (2007).

5. S. Eskin, O. Berkh, G. Rogalsky and J. Zahavi, Plat. Surf. Finish. 85(4), 79 (1998).

6. D. P. Weston, S. J. Harris, H. Capel, N. Ahmed, P. H. Shipway and J. M. Yellup, Trans. Inst. Met. Finish. 88, 47 (2010).

7. M. Mulukutla, V. K. Kommineni and S. P. Harimkar, Appl. Surf. Sci. 258, 2886 (2012).

8. F. -H. Su, C. -S. Liu and P. Huang, Appl. Surf. Sci. 258, 6550 (2012).

9. M. J. Aus, C. Cheung, B. Szpunar, U. Erb and J. Szpunar, J. Mater. Sci. Lett. 17, 1949 (1998).

10. H. J. Yun, S. M. S. I. Dulal, C. B. Shin, C. -K. Kim, Electrochim. Acta 54, 370 (2008).

11. H. Capel, P. H. Shipway and S. J. Harris, Wear 255, 917 (2003).

12. Z. A. Hamid, Mater. Lett. 57, 2558 (2003).

13. P. Bera, H. Seenivasan, K. S. Rajam and V. K. W. Grips, Mater. Lett. 76, 103 (2012).

14. D. Briggs and M. P. Seah, Practical Surface Analysis by Auger and X-ray Photoelectron Spectroscopy, Wiley, New York (1984).

15. H. S. Chen, H. J. Leamy and C. E. Miller, Ann. Rev. Mater. Sci. 10, 363 (1980). 
16. A. Singh, N. Iyer and S. P. Harimkar, J. Appl. Phys. 111, 103508 (2012).

17. V. M. Fedosyuk and J. M. Riveiro, J. Non-Cryst. Solids 143, 153 (1992).

18. N. S. Mclntyre and M. G. Cook, Anal. Chem. 47, 2208 (1975).

19. L. Orlovskaja, E. Matulionis, A. Timinskas and V. Šukienè, Surf. Coat. Technol. 135, 34 (2000).

20. C. N. R. Rao, D. D. Sarma, S. Vasudevan and M. S. Hegde, Proc. R. Soc. Lond. A 367, 239 (1979).

21. M. Donten, J. Solid State Electrochem. 3, 87 (1999).

22. J. Haber, J. Stoch and L. Ungier, J. Solid State Chem. 19, 113 (1976).

23. T. Choudhury, S. O. Saied, J. L. Sullivan and A. M. Abbot, J. Phys. D: Appl. Phys. 22, 1185 (1989).

24. C. D. Wagner, W. M. Riggs, L. E. Davis and J. F. Moulder, Handbook of X-ray Photoelectron Spectroscopy, (Ed.: G. E. Muilenberg), Perkin Elmer Corporation, Eden Prairie (1979) p. 184.

25. C. J. Powell and P. E. Larson, Appl. Surf. Sci. 1, 186 (1978).

26. J. H. Scofield, J. Electron Spectrosc. Relat. Phenom. 8, 129 (1976).

27. D. R. Penn, J. Electron Spectrosc. Relat. Phenom. 9, 29 (1976).

28. W. Hume-Rothery and M. R. J. Wyllie, Proc. Royal Soc. London A 181, 331 (1943).

29. Wear resistant surfaces in engineering-a guide to their production, properties and selection, International Research and Development Co Ltd, London (1986) p. 85. 
30. M. Cymboliste, Trans. Electrochem. Soc. 73, 353 (1938).

31. D. T. Gawne, Thin Solid Films 118, 385 (1984).

32. W. H. Cleghorn, J. M. West, Trans. Inst. Met. Finish. 44, 105 (1966).

33. S. V. N. Naidu, A. M. Sriramamurthy and P. R. Rao, Binary alloy phase diagrams, in: H. Baker (Ed.), ASM Handbook, Vol. 3, ASM International, Materials Park (1992) p. 2.151. 
Table I. Peak temperatures and enthalpy $(\Delta \mathrm{H})$ values obtained from DSC thermograms of Co-W coating at different scanning rates.

\begin{tabular}{|l|l|l|l|l|l|l|}
\hline Scanning rates & Peak 1 & Peak 2 & Peak 3 & $\Delta \mathrm{H} 1$ & $\Delta \mathrm{H} 2$ & $\Delta \mathrm{H} 3$ \\
\hline$\left({ }^{\circ} \mathrm{C} \mathrm{min}{ }^{-1}\right)$ & $\left({ }^{\circ} \mathrm{C}\right)$ & $\left({ }^{\circ} \mathrm{C}\right)$ & $\left({ }^{\circ} \mathrm{C}\right)$ & $\left(\mathrm{J} \mathrm{g}^{-1}\right)$ & $\left(\mathrm{J} \mathrm{g}^{-1}\right)$ & $\left(\mathrm{J} \mathrm{g}^{-1}\right)$ \\
\hline 20 & 145.23 & 316.76 & 479.26 & -14.5141 & -16.2763 & 24.2591 \\
\hline 30 & 159.38 & 334.73 & 492.80 & -11.5445 & -5.3942 & 49.7993 \\
\hline 40 & 165.12 & 340.98 & 502.07 & -11.5879 & -6.7515 & 49.4448 \\
\hline
\end{tabular}


Table II. Binding energies, relative intensities and FWHMs of different Co species as obtained from Co2p spectra of as-deposited and heat treated Co-W coatings.

\begin{tabular}{|c|c|c|c|c|c|c|}
\hline Coatings & $\begin{array}{c}\text { Co } \\
\text { species }\end{array}$ & $\begin{array}{c}\mathrm{E}_{\mathrm{B}} \text { of } \\
\mathrm{Co} 2 \mathrm{p}_{3 / 2} \\
(\mathrm{eV})\end{array}$ & $\begin{array}{c}\text { Relative } \\
\text { intensity } \\
(\%)\end{array}$ & $\begin{array}{c}\text { FWHM of } \\
{\mathrm{Co} 2 \mathrm{p}_{3 / 2}}_{(\mathrm{eV})}\end{array}$ & $\begin{array}{c}\Delta \mathrm{E}_{\mathrm{B}}\left(2 \mathrm{p}_{3 / 2}-2 \mathrm{p}_{1 / 2}\right) \\
(\mathrm{eV})\end{array}$ & $\begin{array}{c}\Delta \mathrm{E}_{\mathrm{B}}\left(2 \mathrm{p}_{3 / 2}-\mathrm{S}\right) \\
(\mathrm{eV})\end{array}$ \\
\hline As-deposited & $\begin{array}{l}\mathrm{Co}^{0} \\
\mathrm{Co}^{2+}\end{array}$ & $\begin{array}{l}778.3 \\
781.7\end{array}$ & $\begin{array}{l}26 \\
74\end{array}$ & $\begin{array}{l}1.89 \\
3.04\end{array}$ & $\begin{array}{l}14.8 \\
15.9\end{array}$ & $\begin{array}{l}- \\
4.3\end{array}$ \\
\hline $600^{\circ} \mathrm{C}$ & $\begin{array}{l}\mathrm{Co}^{0} \\
\mathrm{Co}^{2+}\end{array}$ & $\begin{array}{l}778.1 \\
781.9\end{array}$ & $\begin{array}{l}16 \\
84\end{array}$ & $\begin{array}{l}1.87 \\
3.04\end{array}$ & $\begin{array}{l}14.9 \\
15.8\end{array}$ & $\begin{array}{l}- \\
4.2\end{array}$ \\
\hline $800^{\circ} \mathrm{C}$ & $\mathrm{Co}^{2+}$ & 781.7 & 100 & 3.08 & 15.6 & 4.1 \\
\hline
\end{tabular}


Table III. Binding energies, relative intensities and FWHMs of different W species as obtained from W4f of as-deposited and heat treated $\mathrm{Co}-\mathrm{W}$ coatings.

\begin{tabular}{|c|c|c|c|c|}
\hline Coatings & W species & $\mathrm{E}_{\mathrm{B}}$ of $\mathrm{W}_{4} \mathrm{f}_{7 / 2}$ & Relative & FWHM of \\
& & $(\mathrm{eV})$ & intensity $(\%)$ & $\mathrm{W}_{7 / 2}(\mathrm{eV})$ \\
\hline As-deposited & $\mathrm{W}^{0}$ & 31.4 & 36 & 1.36 \\
& $\mathrm{~W}^{6+}$ & 36.1 & 64 & 1.83 \\
\hline $600{ }^{\circ} \mathrm{C}$ & $\mathrm{W}^{0}$ & 31.0 & 33 & 1.41 \\
& $\mathrm{~W}^{5+}$ & 35.5 & 32 & 1.82 \\
& $\mathrm{~W}^{6+}$ & 36.8 & 35 & 1.81 \\
\hline $800{ }^{\circ} \mathrm{C}$ & $\mathrm{W}^{5+}$ & 35.8 & 26 & \\
& & 36.4 & 74 & \\
\hline
\end{tabular}


Table IV. Relative surface concentrations (at.\%) of Co and W evaluated from XPS of Co-W coatings at different heat treatment conditions.

\begin{tabular}{|c|c|c|}
\hline Coatings & Co & W \\
\hline As-deposited & 87 & 13 \\
\hline $600^{\circ} \mathrm{C}$ & 83 & 17 \\
\hline $800^{\circ} \mathrm{C}$ & 90 & 10 \\
\hline
\end{tabular}


Table V. Microhardness of Co-W coatings at different heat treatment conditions.

\begin{tabular}{|c|c|}
\hline Coatings & Microhardness (HK) \\
\hline As-deposited & $486 \pm 20$ \\
\hline $160^{\circ} \mathrm{C}$ & $538 \pm 20$ \\
\hline $350^{\circ} \mathrm{C}$ & $709 \pm 20$ \\
\hline $500^{\circ} \mathrm{C}$ & $1017 \pm 20$ \\
\hline $600^{\circ} \mathrm{C}$ & $1336 \pm 20$ \\
\hline
\end{tabular}




\section{FIGURE CAPTIONS}

Fig. 1. DSC profile of as-deposited $\mathrm{Co}-\mathrm{W}$ alloy coating at a scan rate of $20{ }^{\circ} \mathrm{C} \mathrm{min}^{-1}$.

Fig. 2. Deconvoluted XPS of Co2p core level of Co-W alloy coatings: (a) as-deposited and (b) after heat treatment at $800{ }^{\circ} \mathrm{C}$.

Fig. 3. Deconvoluted XPS of W4f core level of Co-W alloy coatings: (a) as-deposited and (b) after heat treatment at $600{ }^{\circ} \mathrm{C}$.

Fig. 4. Deconvoluted XPS of O1s core level of Co-W alloy coatings: (a) as-deposited and (b) after heat treatment at $800{ }^{\circ} \mathrm{C}$.

Fig. 5. Variation of microhardness of $\mathrm{Co}-\mathrm{W}$ coatings with heat treatment temperatures. 


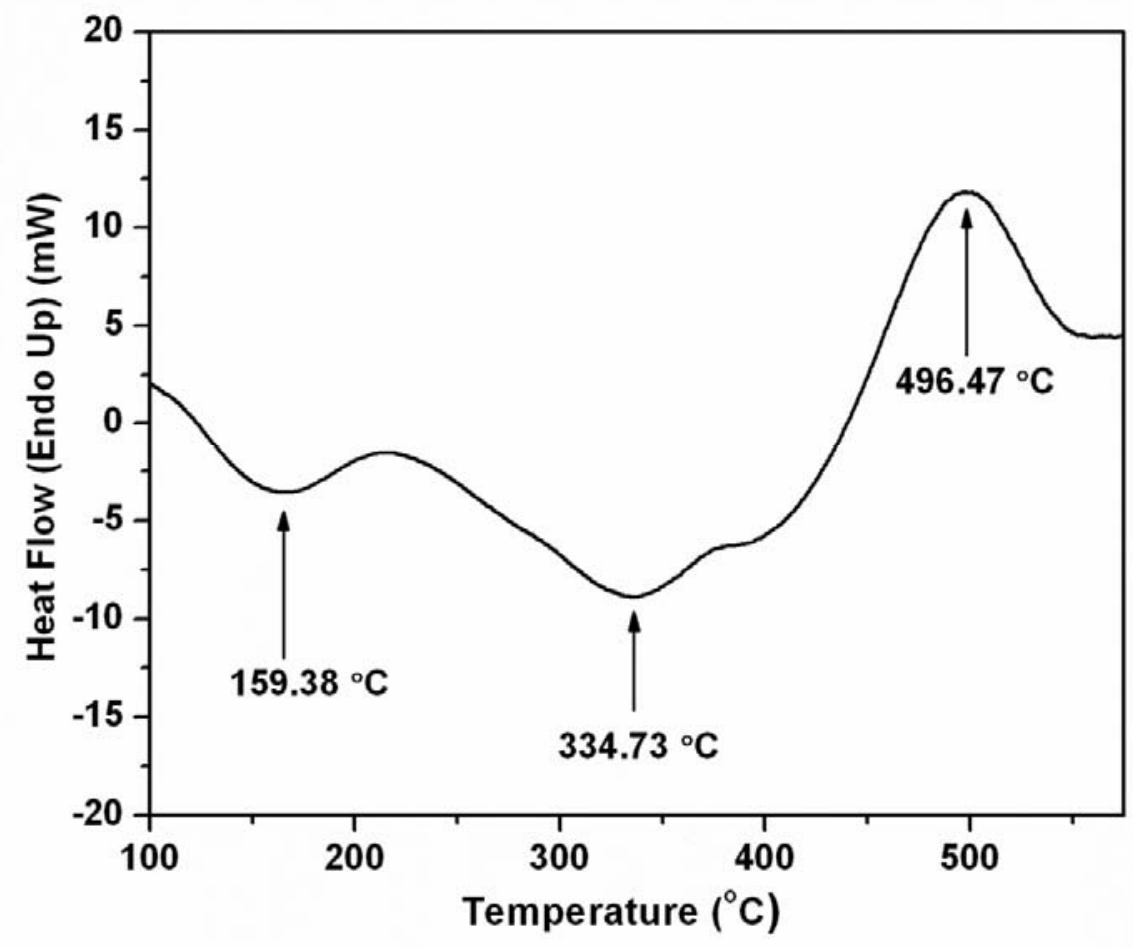

Fig. 1. DSC profile of as-deposited Co-W alloy coating at a scan rate of $20{ }^{\circ} \mathrm{C} \mathrm{min}^{-1}$. 

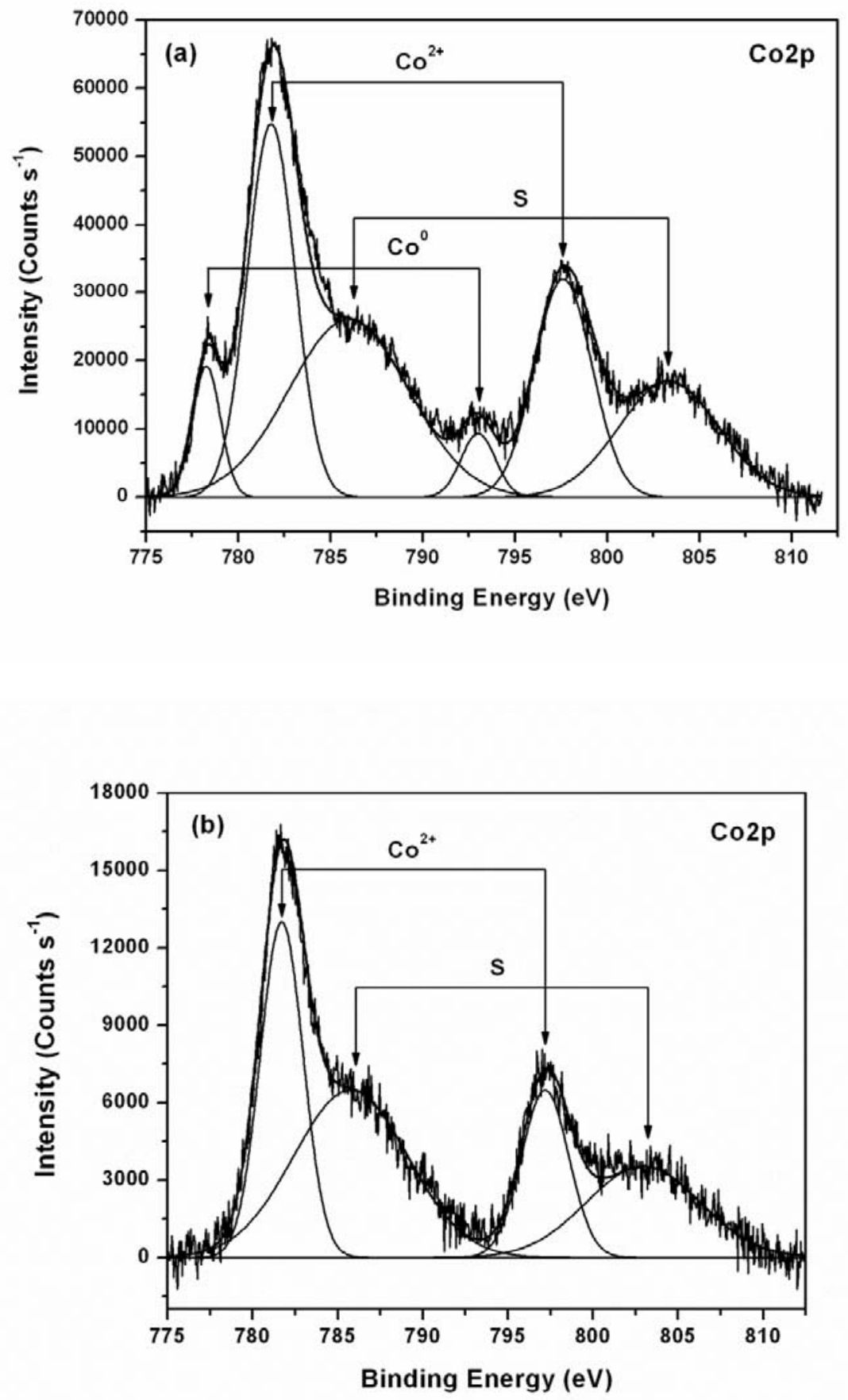

Fig. 2. Deconvoluted XPS of Co2p core level of Co-W alloy coatings: (a) as-deposited and (b) after heat treatment at $800{ }^{\circ} \mathrm{C}$. 

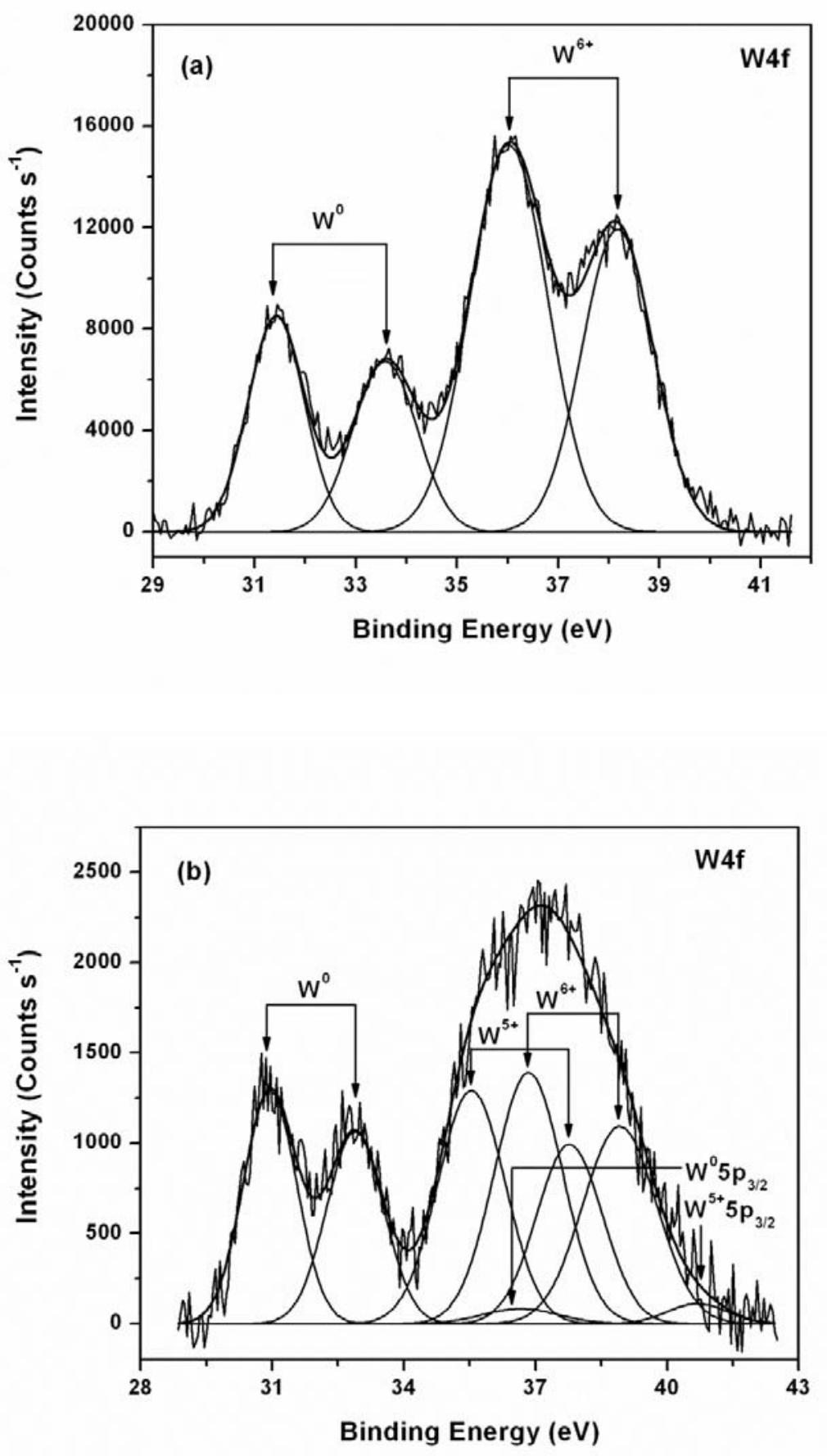

Fig. 3. Deconvoluted XPS of W4f core level of Co-W alloy coatings: (a) as-deposited and (b) after heat treatment at $600{ }^{\circ} \mathrm{C}$. 

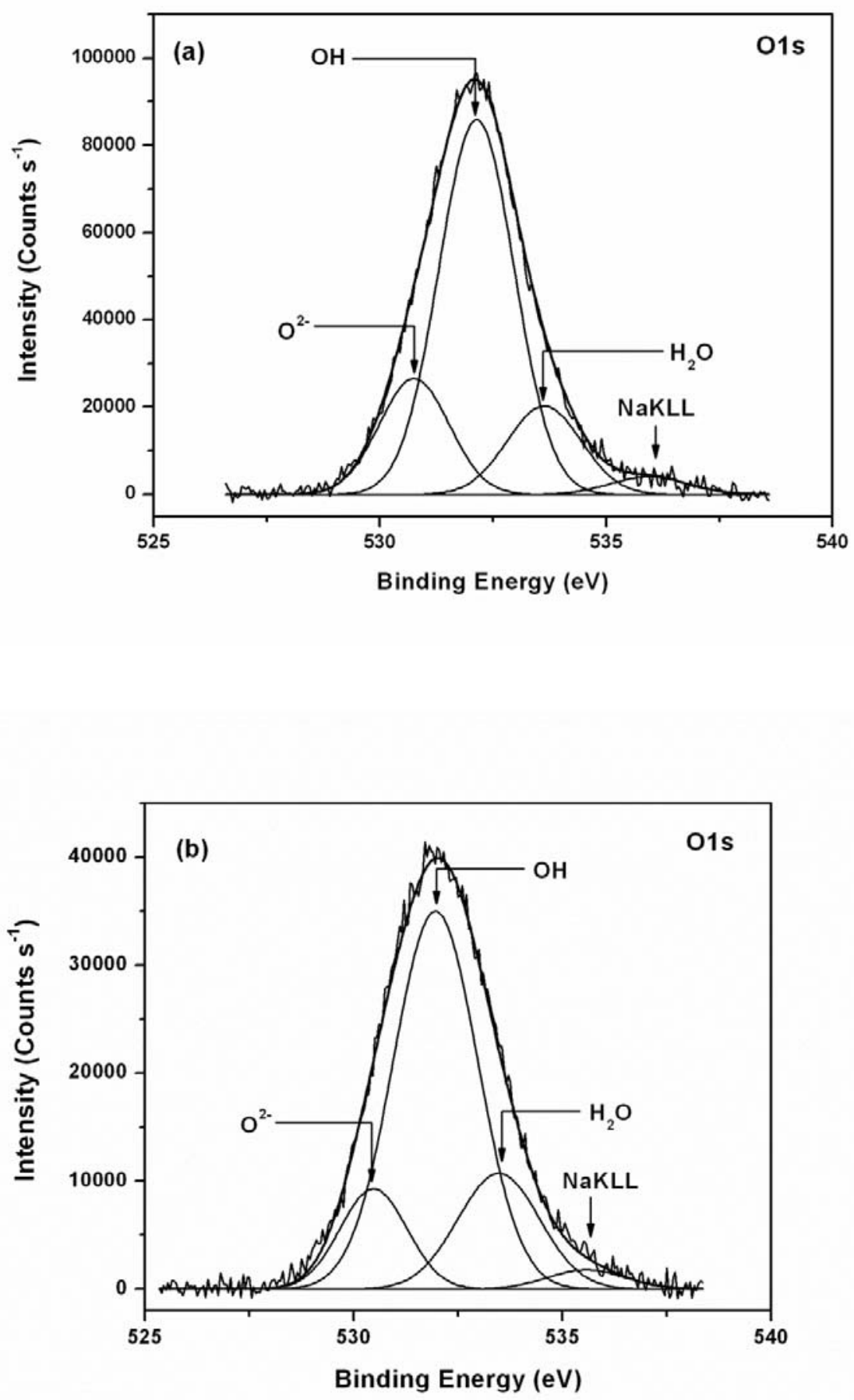

Fig. 4. Deconvoluted XPS of O1s core level of Co-W alloy coatings: (a) as-deposited and (b) after heat treatment at $800{ }^{\circ} \mathrm{C}$. 


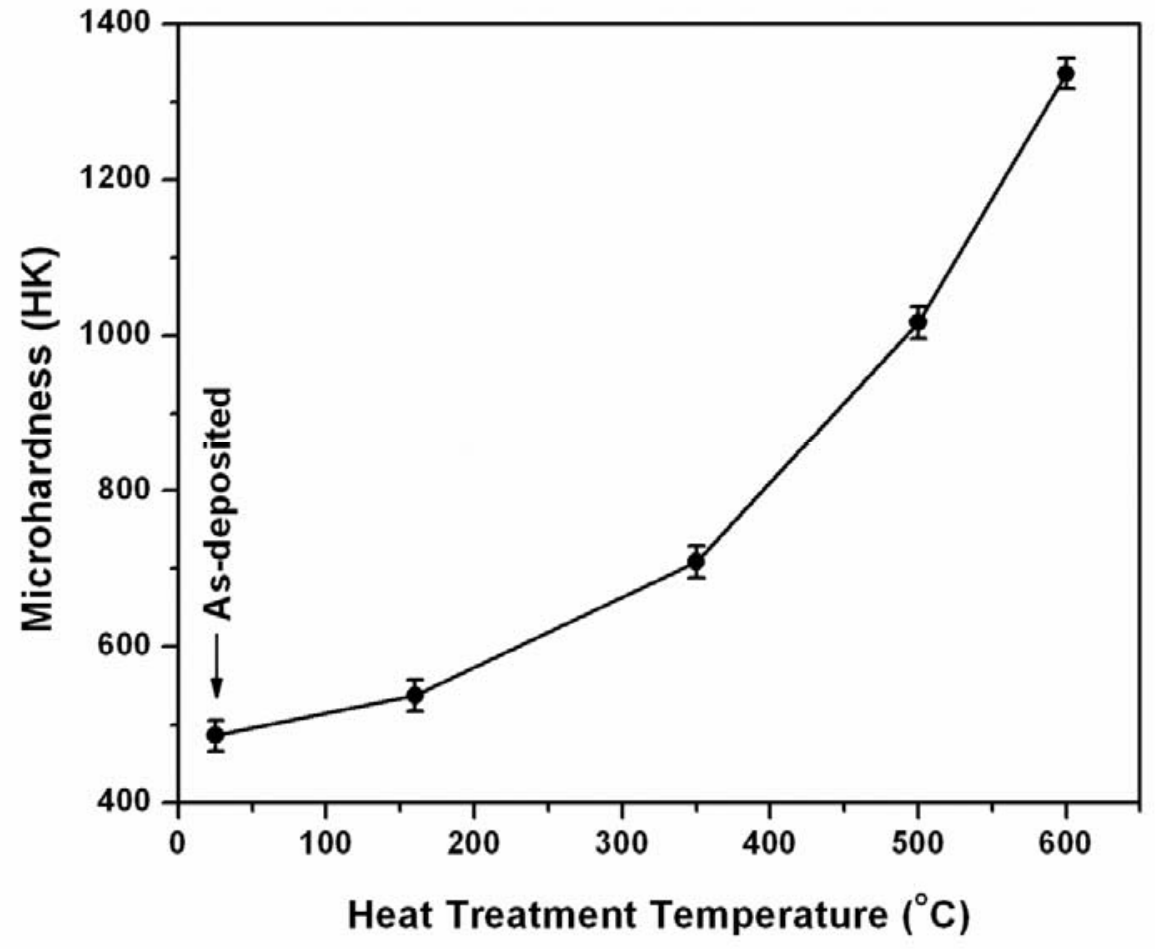

Fig. 5. Variation of microhardness of $\mathrm{Co}-\mathrm{W}$ coatings with heat treatment temperatures. 